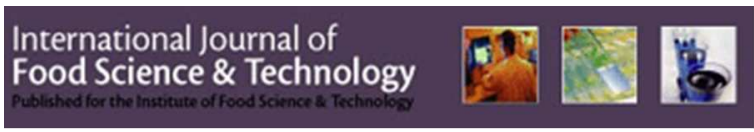

\title{
Dietary fibre enzymatic treatment: a way to improve the rheological properties of high-fibre enriched dough
}

\begin{tabular}{|r|l|}
\hline Journal: & International Journal of Food Science and Technology \\
\hline Manuscript ID: & IJFST-2013-12811.R1 \\
\hline Danuscript Type: & Short Communication \\
\hline Complete List of Authors: & $\begin{array}{l}\text { Marti, Alessandra; University of Milan, DeFENS, Department of Food, } \\
\text { Environmental and Nutritional Sciences } \\
\text { Bottega, Gabriella; University of Milan, DeFENS, Department of Food, } \\
\text { Environmental and Nutritional Sciences } \\
\text { Casiraghi, Maria; University of Milan, DeFENS, Department of Food, } \\
\text { Environmental and Nutritional Sciences } \\
\text { Faoro, Franco; University of Milan, DiSAA, Department of Agricultural and } \\
\text { Environmental Sciences - Production, Landscape, Agroenergy } \\
\text { Iametti, Stefania; University of Milan, DeFENS, Department of Food, } \\
\text { Environmental and Nutritional Sciences } \\
\text { Pagani, M. Ambrogina; University of Milan, DeFENS, Department of Food, } \\
\text { Environmental and Nutritional Sciences }\end{array}$ \\
\hline Keywords: & \begin{tabular}{l} 
Dietary Fibre, Enzymes, Dough, Rheology \\
\hline
\end{tabular} \\
\hline \multicolumn{2}{|c}{} \\
\hline
\end{tabular}

\section{SCHOLARONE $^{\text {m }}$}

Manuscripts 
1 Dietary fibre enzymatic treatment: a way to improve the rheological properties of high-fibre enriched 2 dough

3

4 Alessandra Marti ${ }^{1}$, Gabriella Bottega ${ }^{1}$, Maria Cristina Casiraghi ${ }^{1}$, Franco Faoro ${ }^{2}$, Stefania Iametti ${ }^{1}$, $5 \quad$ Maria Ambrogina Pagani ${ }^{1 *}$

$6{ }^{1}$ Department of Food, Environmental and Nutritional Sciences - Università degli Studi di Milano, via 7 Giovanni Celoria 2, 20133 Milan, Italy

$8 \quad 2$ Department of Agricultural and Environmental Sciences - Production, Landscape, Agroenergy $9 \quad$ Università degli Studi di Milano, via Giovanni Celoria 2, 20133 Milan, Italy

$11 *$ Corresponding author:

12 Prof. Maria Ambrogina Pagani

132 , Via G. Celoria

1420133 Milan, Italy

15 E-mail: ambrogina.pagani@unimi.it

16 Phone: +390250316658 
The demand for functional products is increasing, driven largely by the market interest in foods suitable for improving the health and well-being of consumers (Charalampopoulos et al., 2002). In this regard, diets rich in dietary fibre (DF) are more and more recommended, since it is widely accepted that NonStarch Polysaccharides (NSP) are associated with the prevention of cardiovascular diseases, the regulation of intestinal function, the promotion of gut health, and the protection against colon cancer (Kumar et al., 2012). Bakery products, particularly bread, may be a convenient tool for increasing DF content in habitual western diet, since they are consumed daily in high amounts.

However, the long chains in NSP molecules interfere with the development of a regular and strong gluten network, resulting in a worsening of the rheological properties and handling of bread dough, giving loaf with low volume, hard crumb, bitter flavour, and dark colour (Ktenioudaki \& Gallagher, 2012). The negative effect of fibre on bread texture and consumer acceptability is greatly dependant on the type and components, level of substitution, and particle size of the fibre (Ktenioudaki \& Gallagher, 2012). Many approaches have been employed to improve the quality of fibre-enriched bread, mainly based on the use of bioprocessing such as fermentation (Salmenkallio-Marttila et al., 2001; Katina et al., 2006) and/or on the addition of enzymes or additives directly in the bread formulation (Laurikainen et al., 1998; Haros et al., 2001; Katina et al., 2006; Shah et al., 2006). Consequently, in all these studies the enzymatic action is simultaneous to the bread-making process. None of the enzymatic treatments already proposed has been carried out as a pre-treatment of the fibre. Only Napolitano et al. (2006) highlighted that the conversion of the highly polymerised insoluble dietary fibre of durum wheat into soluble feruloyl oligosaccharides can be achieved by using hydrolytic enzymes. However, no information is available on the effect of fibre enzymatic treatment on the rheological properties of wheat dough when total fibre content is higher than $6 \%$. The aim of the present work was to investigate the modifications induced by enzymatic treatment of fibre on the rheological properties of fibreenriched bread dough. 
42 Oat bran (cv. Raisio, Finland) containing 15\% beta-glucans (BG15; total starch = $26 \mathrm{~g} / 100 \mathrm{~g}$; protein = $4319 \mathrm{~g} / 100 \mathrm{~g}$; lipids = $10 \mathrm{~g} / 100 \mathrm{~g}$;) was used in this study. The enzymatic hydrolysis of the samples was 44 performed with a commercial food grade cellulolytic and glycosidic enzyme mixture (Cytolase M102, 45 Genencor International, New York, USA, with a cellulase activity of 2400 viscosimetric units, 46 14 47 enzyme solution was added to one gram of sample suspended in $4 \mathrm{ml}$ of deionised water. The 48 suspension was placed in agitation for 6 hours at $25^{\circ} \mathrm{C}$, then freeze dried, according to Caldini et al. 49 (1994). The amount of total (DF), soluble (SDF) and insoluble dietary fibre (IDF) was determined 50 according to the gravimetric enzymatic method proposed by Prosky et al. (1988). The soluble residue 51 in the supernatant was measured after centrifugation of the mixture at $4000 \times \mathrm{g}$, for $15 \mathrm{~min}$ at $25^{\circ} \mathrm{C}$, and 52 overnight drying at $105^{\circ} \mathrm{C}$. Sugar content was determined according to Zygmunt et al. (1982). 53 Microscopy images were obtained by means of an Olympus BX50 microscope, using Lugol $\left(\mathrm{I}_{2} \mathrm{KI}\right)$ as 54 staining.

55 Untreated and treated fibre samples were added to a common wheat flour of good baking properties $56 \quad\left(\right.$ protein $=13.8 \mathrm{~g} / 100 \mathrm{~g} ;$ fiber content $2.95 \mathrm{~g} / 100 \mathrm{~g} ;$ alveographic $\mathrm{W}=358 * 10^{-4} \mathrm{~J} ;$ alveographic $\mathrm{P} / \mathrm{L}=$

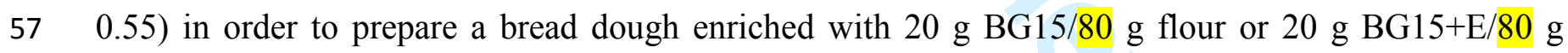
58 flour. Dough mixing properties were evaluated with the farinographic test (Brabender OHG, Duisburg, 59 Germany). Dough development and $\mathrm{CO}_{2}$ produced from the yeast activity during the leavening phase 60 were measured by means of a Rheofermentometer F3 (Chopin, Tripette \& Renaud, Villeneuve La 61 Garenne, France).

62 The data were processed by Statgraphic Plus for Windows v. 5.1. (StatPoint Inc., Warrenton, VA, 63 USA). A one-way analysis of variance (Anova) was performed using the Least Significant Differences 64 (LSD) test to compare the sample means; differences were considered significant at $\mathrm{P}<0.05$. 
65 The enzymatic treatment of fibre was associated with a significant decrease in the total fibre content 66 (Table 1). In particular, the SDF/IDF ratio greatly changed; this trend could be related to the formation 67 of disaccharides and/or other soluble oligosaccharides having size and molecular weight too low to be 68 classified as SDF by using the Prosky method (Prosky et al., 1988). This finding was confirmed by a 69 significant increase of the soluble residue and by the higher sugar content measured after enzymatic treatment (Table 1). The relevant breakdown of the macrostructure of NSP into smaller species was also made evident by microscopy (Fig. 1). Before the enzymatic treatment, BG15 sample appears characterized by fibre particles between 500 and $650 \mu \mathrm{m}$ in size (Fig. 1a). The enzymatic action caused 73 a disintegration of the fibre particles, broken down to fractions in the 20-100 $\mu \mathrm{m}$ range (Fig. 1b).

74 The effects of the enrichment in fibre on mixing properties, as evaluated by the farinographic test, are 75 reported in Fig. 2. As expected, the water absorption and the development time of the flour increased, 76 whereas the stability decreased. The high water affinity of the NSP and the weakening effect of fibre on dough have been already described (Sudha et al., 2007). On the contrary, adding high level of untreated fibre resulted in an increase of both water absorption of the dough and development time, accounting for a difficult workability. Adding enzymatically treated fibre promoted a decrease of the amount of water absorption and a more relevant impact on the macromolecule hydration and, consequently, on the development time (see insert in Fig. 2).

The dough development during leavening and the amount of gas produced and retained by the dough system of the dough enriched with fibre was investigated by the rheofermentographic test. The addition of untreated fibre compromised a good dough development (Fig. 3). This phenomenon had been attributed to impaired protein hydration in presence of NSP (Sudha et al., 2007). The addition of pretreated fibre allowed a fast and great dough development, likely due to the sugar formation promoted by the enzymatic treatment. With regard to the ability of the dough to produce $\mathrm{CO} 2$, the incorporation 
88 of BG15+E to flour resulted in a product with high gas production and retention, very similar to that 89 obtained for the common wheat flour (see insert in Fig. 3).

90 These results suggest that the enzymatic treatment allows to add high level of soluble fibre (>5\%) to 91 the flour without worsening the dough properties during both mixing and leavening. The enzymatic 92 pre-treatment proposed in this study may be easily applied by milling companies both for the 93 enhancement of wheat milling by-products and for increasing their range of products. From the point of 94 view of the final user, in a production reality as the Italian one, characterized by numerous small bread95 making companies where very often experience and tradition matter more than a scientific approach, 96 the use of pre-treated flours/ingredients permits to minimize some of the problems associated with the 97 direct use of enzymes in bread-making.

98 Further studies are currently being carried out to investigate the effect of treated fibre on bread 99 characteristics.

\section{References}

Caldini, C., Bonomi, F., Pifferi, P.G., Lanzarini, G., Galante, Y.M. (1994). Kinetic and immobilization studies on fungal glycosidases for aroma enhancement in wine. Enzyme and Microbial Technology, 16, 286-291.

Charalampopoulos, D., Wang, R., Pandiella, S.S., Webb, C. (2002). Application of cereals and cereal components in functional food: a review. International Journal of Food Microbiology, 79, 131-141.

Haros, M., Rosell, C. M., Benedito, C. (2001). Use of fungal phytase to improve breadmaking performance of whole wheat bread. Journal of Agricultural and Food Chemistry, 49, 5450-5454. 
109 Katina, K., Salmenkallio-Marttila, M., Partanen, R., Forssell, P., Autio, K. (2006). Effects of sourdough 110 and enzymes on staling of high-fibre wheat bread. LWT - Food Science and Technology, 39, 479-491.

111 Ktenioudaki, A., Gallagher, E. (2012). Recent advances in the development of high-fibre baked 10

Kumar, V., Sinha, A.K., Makkar, H.P.S., De Boeck, G., Becker, K. (2012). Dietary roles of Non-Starch Polysaccharides in human nutrition: a review. Critical Reviews in Food Science and Nutrition, 52, 899935.

Laurikainen, T., Harkonen, H., Autio, K., Poutanen, K. (1998). Effects of enzymes in fibre-enriched baking. Journal of the Science of Food and Agriculture, 76, 239-249.

Napolitano, A., Lanzuise, S., Ruocco, M., Arlotti, G., Ranieri, R., Knutsen, S.H., Lorito, M., Fogliano, V. (2006). Treatment of cereal product with tailored preparation of Trichoderma enzymes increases the amount of soluble dietary fiber. Journal of Agricultural and Food Chemistry, 54, 7863-7869.

Prosky, L., Asp, N.G., Schweizer, T.F., DeVries, J.W., Furda, I. (1998). Determination of unsoluble, soluble, and total dietary bran foods and food products. Interlaboratory study. Journal of Association of Official Analytical Chemists, 71, 1017-1023.

Salmenkallio-Marttila, M., Katina, K., Autio, K. (2001). Effects of bran fermentation on quality and microstructure of high-fiber wheat bread. Cereal Chemistry, 78, 429-435.

Shah, A.R., Shah, R.K., Madamwar, D. (2006). Improvement of the quality of whole wheat bread by supplementation of xylanase from Aspergillus foetidus. Bioresource Technology, 97, 2047-2053. 
128 Sudha, M.L., Vetrimani, K., Leelavathi. K. (2007). Influence of fibre from different cereals on the 129 rheological characteristics of wheat flour dough and on biscuit quality. Food Chemistry, 100, $1365-$ 13 14 15

131 Zygmunt, L.C., Anderson, E., Behrens, B., Bowers, R., Bussey, M., Cohen, G., Colon, M., Deis, C., 132 Given, P.S., Granade, A., Harms, C., Heroff, J.C., Hines, D., Hung, G.W., Hurst, W.J., Keller, J., 133 Laroche, F.B., Luth, W., McKay, D., Mertle, T., Navarre, M., Rivera, R., Scopp, R., Scott, F., 134 Sherman, R., Sloman, K., Sodano, C., Trick, K.D., Vandine, B.R., Webb, N.G. (1982). High pressure 135 liquid chromatographic determination of mono and disaccharides in pre-sweetened cereals: 136 collaborative study. Journal of Association of Official Analytical Chemists, 65, 256-264. 
137 Table 1. Fibre and sugars content $(\mathrm{g} / 100 \mathrm{~g} \mathrm{db})$ of untreated and enzymatically treated high fibre 138 samples.

7

139 BG15 = oat bran (15\% beta-glucans); BG15+E = enzymatically treated oat bran (15\% beta-glucans).

Figure 1. Microscope images of untreated (a) and enzymatically treated (b) high fibre samples.

BG15 = oat bran (15\% beta-glucans); BG15+E = enzymatically treated oat bran (15\% beta-glucans).

Figure 2. Mixing properties of untreated and treated fibres.

BG15 = oat bran (15\% beta-glucans $) ;$ BG15+E = enzymatically treated oat bran (15\% beta-glucans $).$

BG15 = oat bran (15\% beta-glucans $) ;$ BG15+E = enzymatically treated oat bran (15\% beta-glucans $).$ 
147 Table 1. Fibre and sugars content of untreated and enzymatically treated high fibre samples.

148 BG15 = oat bran (15\% beta-glucans $) ;$ BG15+E = enzymatically treated oat bran (15\% beta-glucans).

7

149

9

10150

11

12

13151

14

15152

16

17

$18^{153}$

19

20154

21

22155

23

24

25156

26

27157

28

29158

30

31

32159

33

34160

35

36161

37

38162

39

40163

\begin{tabular}{|c|c|c|}
\hline \multirow{2}{*}{ Parameters } & BG15 & $\mathrm{BG} 15+\mathrm{E}$ \\
\hline & \multicolumn{2}{|c|}{$(g / 100 \mathrm{~g} \mathrm{db})$} \\
\hline Total Fibre & $31.10 \pm 0.93 b$ & $24.10 \pm 0.72 \mathrm{a}$ \\
\hline Soluble Fibre & $15.36 \pm 0.46 \mathrm{a}$ & $20.23 \pm 0.61 b$ \\
\hline Insoluble Fibre & $15.69 \pm 0.47 b$ & $3.89 \pm 0.12 \mathrm{a}$ \\
\hline Soluble/Insoluble Fibre ratio & 0.98 & 5.2 \\
\hline Soluble residue & $11.8 \pm 0.35 b$ & $23.5 \pm 0.71 \mathrm{a}$ \\
\hline Sugars & $3.16 \mathrm{a}$ & $5.19 b$ \\
\hline Glucose & $0.03 \pm 0.001 \mathrm{a}$ & $3.22 \pm 0.04 b$ \\
\hline Fructose & $0.07 \pm 0.002 \mathrm{a}$ & $1.10 \pm 0.005 b$ \\
\hline Sucrose & $2.34 \pm 0.01 b$ & $0.18 \pm 0.02 \mathrm{a}$ \\
\hline Maltose & $0.40 \pm 0.05 b$ & $0.27 \pm 0.04 \mathrm{a}$ \\
\hline
\end{tabular}

Different letters in the same line are significantly different (Least Significant Differences; $\mathrm{p}<0.05$ ). 


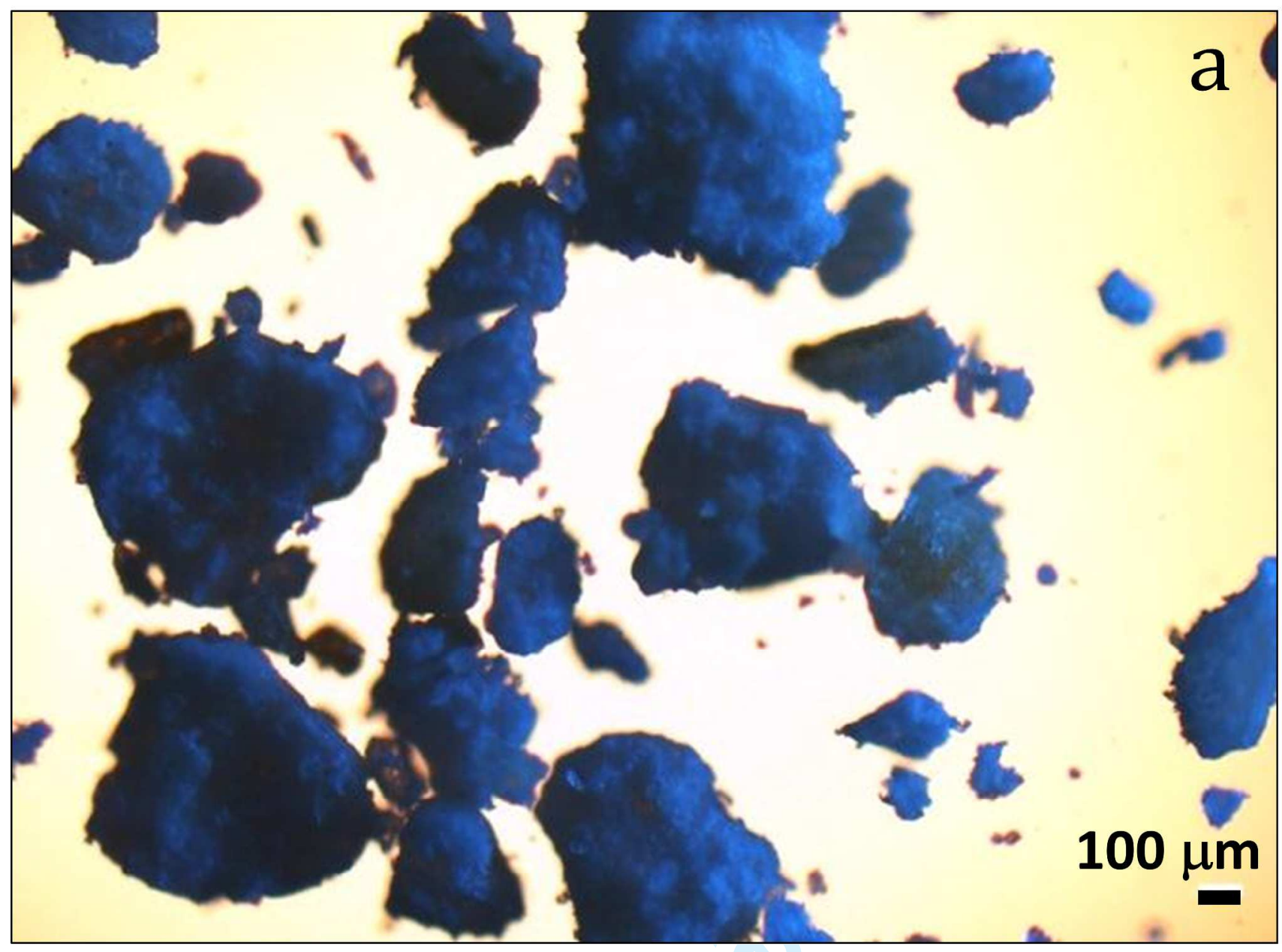

39

40 


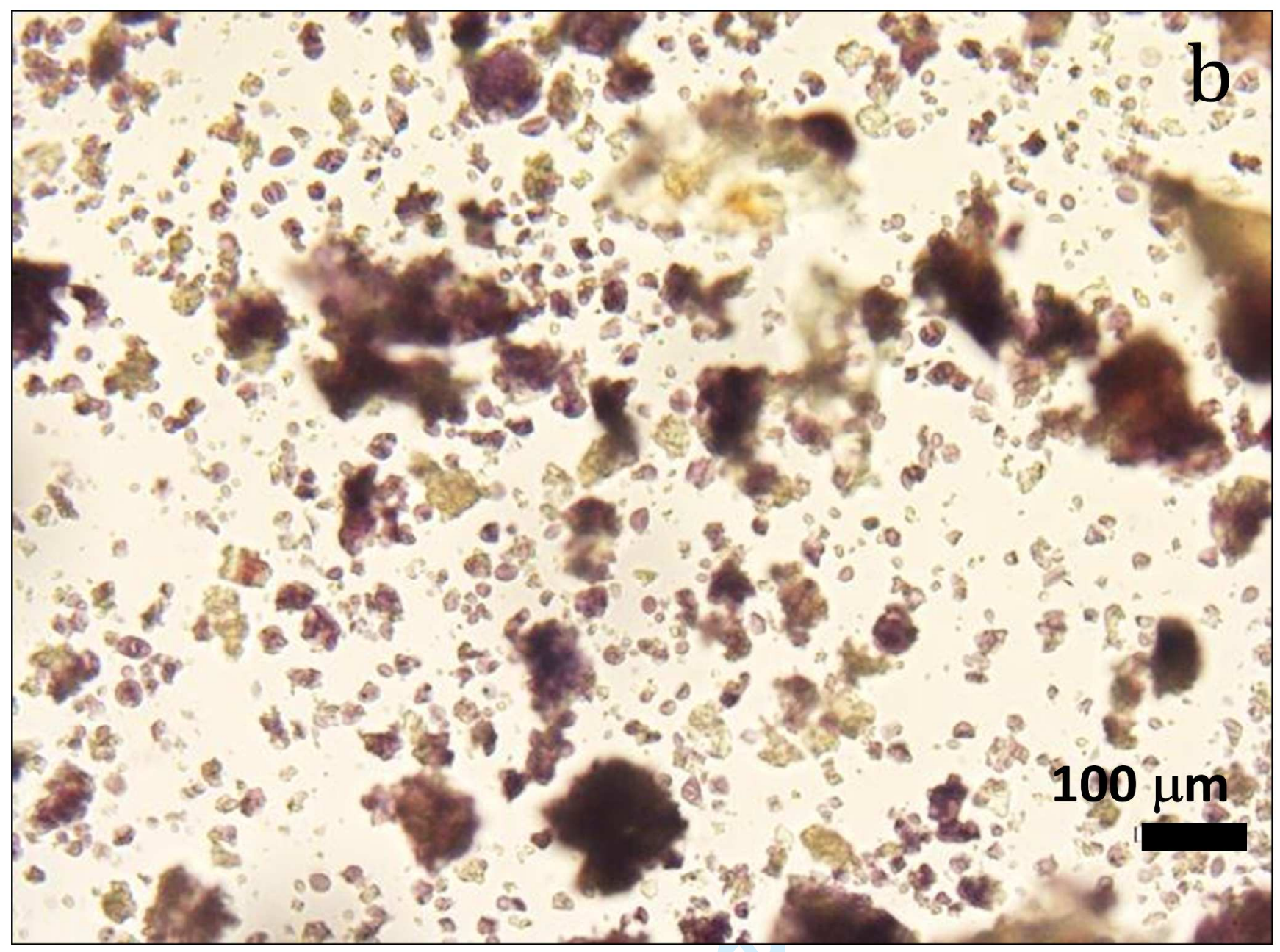

176 Figure 1. Microscope images of untreated (a) and enzymatically treated (b) high fibre samples.

177 BG15 = oat bran (15\% beta-glucans); BG15+E = enzymatically treated oat bran (15\% beta-glucans). 


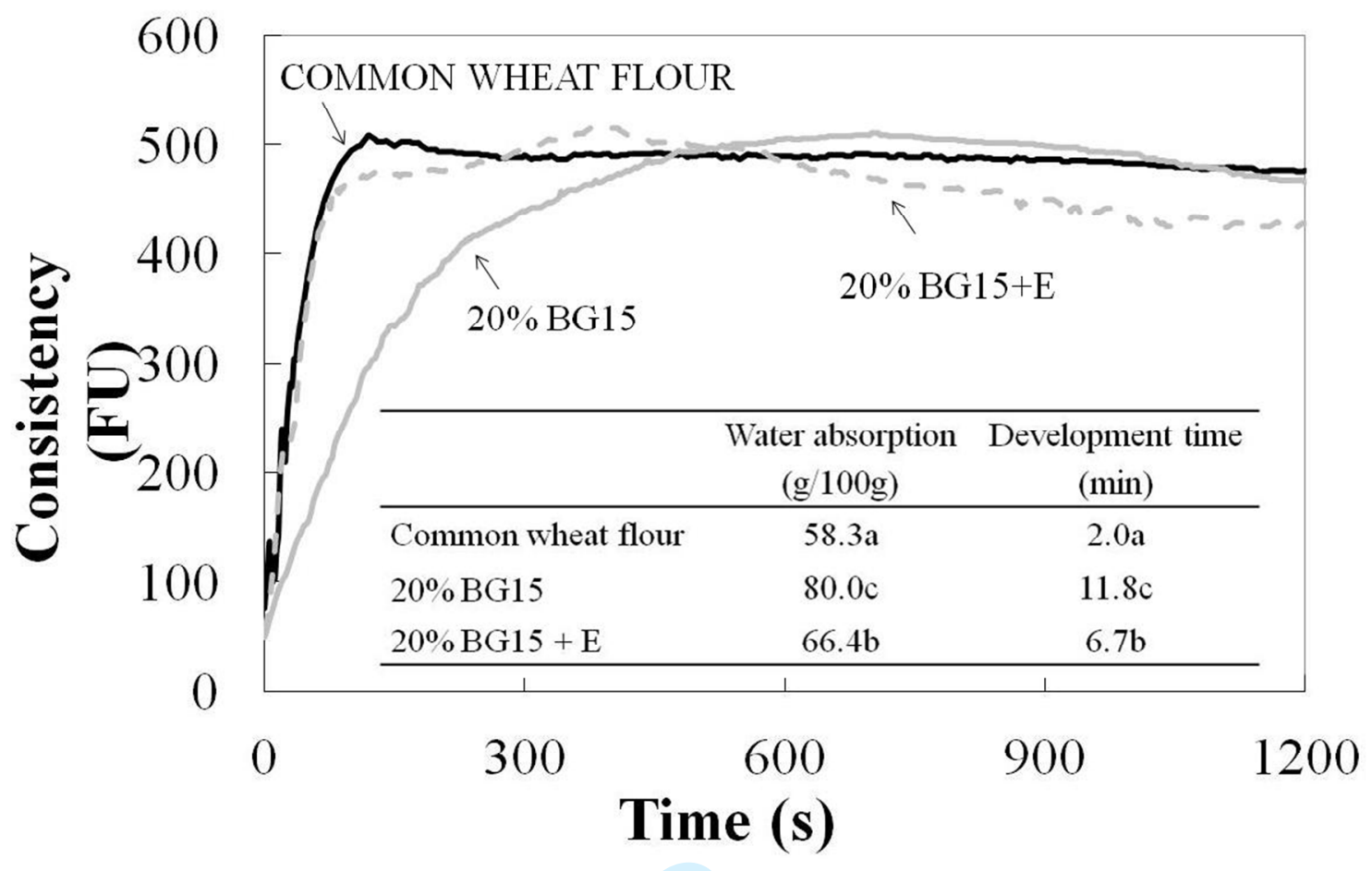

180 Figure 2. Mixing properties of untreated and treated fibres. 


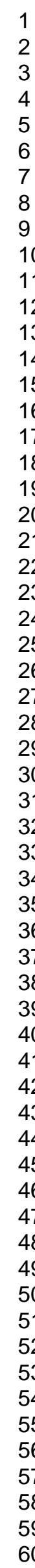

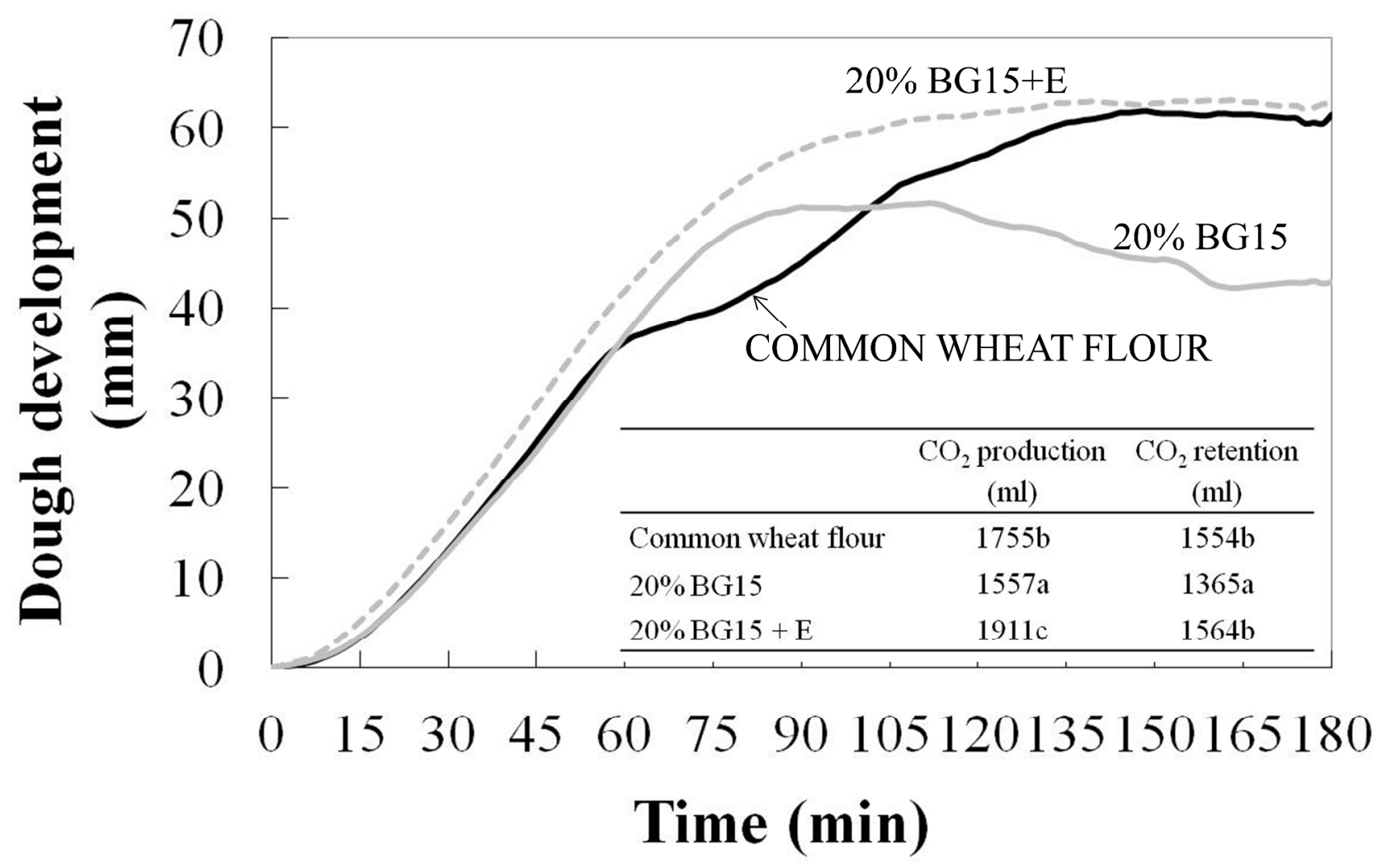

184 Figure 3. Leavening properties of fibre-enriched wheat dough. Different letters in the same parameter 185 are significantly different (Least Significant Differences; $\mathrm{p}<0.05$ ).

186 BG15 = oat bran (15\% beta-glucans); BG15+E = enzymatically treated oat bran (15\% beta-glucans). 